\title{
JOGOS EDUCACIONAIS: CONTRIBUIÇÕES DA NEUROCIÊNCIA À APRENDIZAGEM
}

\author{
Educational Games: Contributions of Neuroscience to Learning
}

\author{
Daniela Karine RAMOS, UFSC ${ }^{1}$ \\ Caroline Chioquetta LORENSET, IFSC ${ }^{2}$ \\ Giani PETRI, UFSM ${ }^{3}$
}

\begin{abstract}
RESUMO: Este artigo tem como objetivo discutir as características dos jogos educacionais e suas contribuições à aprendizagem, procurando estabelecer relações com os conhecimentos da neurociência. Para tanto, foi realizada uma pesquisa teórica para sistematização de conceitos, características e elementos presentes nos jogos, como regras e restrições, narrativa, objetivos, interação, desafio, competição e conflito, resultados, recompensas e feedback, destacando suas contribuições à aprendizagem. Além disso, a pesquisa teórica abordou a cognição e a aprendizagem, apresentando considerações importantes de Vygotsky, como a mediação, a Zona de Desenvolvimento Proximal e as funções executivas. Ao mesmo tempo, apresenta conceitos da neurociência que reforçam as contribuições do uso dos jogos educacionais para a aprendizagem.
\end{abstract}

PALAVRAS-CHAVE: Jogos educacionais; Neurociência; Cognição; Aprendizagem.

ABSTRACT: This article aims to discuss the characteristics of educational games and its contributions to education, seeking to establish associations to neuroscience influences. Therefore, theoretical research was conducted for the systematization of concepts, characteristics and elements present in educational games, such as rules and restrictions, narrative, objectives, interaction, challenge, competition and conflict, and results, rewards and feedback, highlighting its contributions to the learning process. Moreover, the theoretical research addresses concepts as cognition and learning, presenting important theoretical considerations of Vygotsky, such as mediation, Zone of Proximal Development and executive functions. At the same time, the article introduces concepts of neuroscience that reinforce the contributions of educational games for meaningful learning.

KEYWORDS: Educational games; Neuroscience; Cognition; Learning.

\footnotetext{
${ }^{1}$ Doutora em Educação e professora da Universidade Federal de Santa Catarina (UFSC). dadaniela@ gmail.com

${ }^{2}$ Doutoranda (UFSC) e docente de língua inglesa do Instituto Federal de Educação, Ciência e Tecnologia de Santa Catarina. carol.lorenset@gmail.com

${ }^{3}$ Doutorando (UFSC) e docente dos cursos da área de Informática na Universidade Federal de Santa Maria (UFSM). gianipetri@gmail.com
} 


\section{INTRODUÇÃO}

A inserção de tecnologias educacionais em espaços escolares vem crescendo gradativamente e provocando mudanças na educação (Moran, 2013). As habilidades tecnológicas inerentes ao perfil do aluno atual os acompanham em sala de aula. Desse modo, as habilidades, experiências e conhecimentos prévios dos alunos tornam-se importantes fontes a serem valorizadas e exploradas pelos professores no planejamento e mediação pedagógica.

Neste contexto, a utilização de jogos educacionais (digitais e não digitais) como estratégia de ensino vem se tornando uma ferramenta inovadora, de modo que potencializam uma aprendizagem ativa e mais significativa (Wagner, 1970), onde os alunos (jogadores) constroem conhecimentos a partir de suas próprias experiências (Bonwell \& Eison, 1991). Além disso, um jogo educacional configura-se como uma estratégia instrucional que envolve competição e está organizada por regras e restrições para alcançar um determinado objetivo (Dempsey et. al, 1996). E, de acordo com Gramigna (2007), os jogos educacionais contribuem na aprendizagem dos alunos, potencializando a experimentação e visualização de conceitos, além de criar ambientes que despertam a criatividade e o interesse dos alunos.

Os jogos educacionais são caracterizados por vários elementos presentes nos jogos, de modo geral, e oferecem contribuições à aprendizagem. Elementos como: objetivos, regras, restrições; interação; desafio, competição, recompensas e feedback (Prensky, 2007; Wangenheim \& Wangenheim, 2012) contribuem para a aprendizagem e para o desenvolvimento das habilidades cognitivas dos jogadores.

Considerando a aproximação com o campo educacional, a aprendizagem e os aspectos cognitivos, apoiamo-nos também na perspectiva de Vygotsky (2007), especialmente em seus estudos sobre as funções psicológicas superiores, para relacionar o uso dos jogos educacionais ao exercício de habilidades como: atenção, percepção, interação social e emoção. Em paralelo, neurocientistas buscam evidências científicas em entender como o cérebro aprende e como os elementos do contexto educacional contribuem para que o processo de aprendizagem se efetive.

Diante disso, este artigo tem como objetivo discutir as características dos jogos educacionais digitais e não-digitais e suas contribuições à aprendizagem, procurando estabelecer relações com os conhecimentos da neurociência. Primeiramente, apresentamos os jogos educacionais, trazendo aporte teórico histórico até a chegada dos jogos educacionais digitais utilizados atualmente. Em seguida, focamos nos benefícios dos jogos educacionais digitais e da neurociência à aprendizagem no geral, para, posteriormente, focarmos na 
aprendizagem de línguas estrangeiras através dos jogos. Para tanto, realizamos uma pesquisa de caráter teórico, visando aprofundar e discutir conhecimentos sobre as contribuições dos jogos educacionais à aprendizagem.

\section{JOGOS EDUCACIONAIS: CONCEITOS E CARACTERÍSTICAS}

Nesta seção, faremos uma breve explanação teórica sobre jogos educacionais, dando enfoque maior em suas contribuições para a aprendizagem.

Os jogos estão presentes na vida humana desde os primórdios de nossa civilização, podendo ser considerado como função de vida, entretanto, não é passível de definição exata (Huizinga, 1996). Diante disso, várias tentativas e aproximações são feitas para conceituar o jogo. Thompson, Berbank-Green \& Cusworth (2007) definem o jogo como uma atividade recreativa conduzida por um ou mais jogadores que competem para alcançar metas, respeitando as regras e restrições preestabelecidas. O conceito de jogo é encontrado de diversas formas na literatura, no entanto, Salen e Zimmerman (2003) ao analisarem um conjunto de definições de jogos concluíram que a maioria dos conceitos faz referência a termos comuns, tais como: regras, metas, diversão e fantasia.

Além disso, os jogos são considerados elemento da cultura (Huizinga, 1996) e tem se tornado um fenômeno cada vez mais presente em nossa sociedade, por seu inegável impacto no entretenimento e em outras áreas como educação e marketing (Santaella e Feitoza, 2009). O uso dos jogos em processos de ensino é registrado desde a criação dos primeiros (Thompson, Berbank-Green and Cusworth, 2007; Hinebaugh, 2009). Registra-se que os primeiros jogos com objetivos educacionais visavam melhorar algumas competências e testar se os jovens estavam aptos para assumir as responsabilidades de adultos em tribos da África (Hinebaugh, 2009).

Nesse sentido, o conceito de jogos educacionais vai além das características originais de um jogo de entretenimento puramente, pois também deve ser educacional, ou seja, deve ser projetado para ensinar um conteúdo em específico (Abt, 2002; Wangenheim \& Wangenheim, 2012). Assim sendo, um jogo para ser considerado educacional, além de envolver competição, regras e restrições, precisa ter objetivos educacionais bem definidos (Abt, 2002). Desse modo, podemos definir que um jogo educacional é qualquer atividade de formato instrucional ou que estimule a aprendizagem, que envolva competição e seja organizada por regras e restrições para alcançar um determinado objetivo educacional (Dempsey et al., 1996). Esses jogos são 
projetados especificamente para ensinar conteúdos específicos ou para reforçar a aprendizagem de habilidades (Abt, 2002).

Os jogos são compostos por um conjunto de elementos que, por si só, potencializam sua utilização como estratégia de ensino experiencial. Os elementos presentes nos jogos são apresentados na Figura 1.

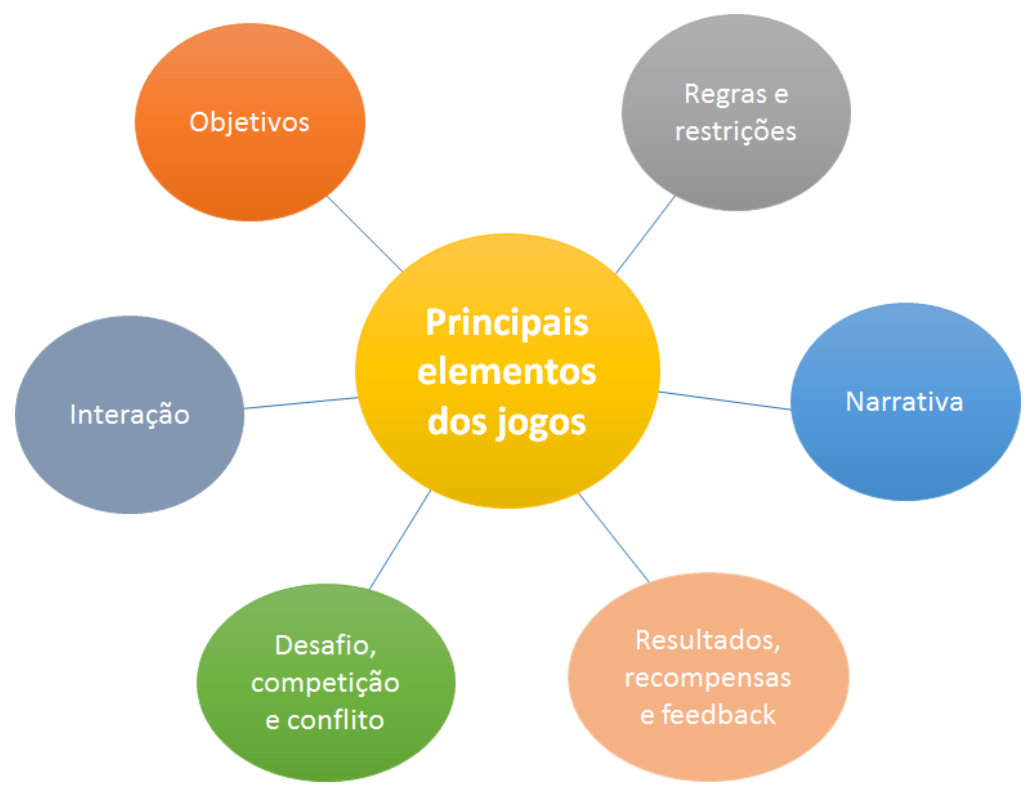

Figura 1 - Elementos presentes nos jogos (Prensky, 2007; Wangenheim \& Wangenheim, 2012)

Todo jogo possui um objetivo que guia/orienta o jogador nas fases do jogo. Por exemplo, chegar em primeiro lugar, com a maior pontuação ou no menor tempo. Os objetivos e as metas de um jogo têm, sobretudo, a função de motivar o jogador e pautar a mensuração de seu desempenho, quanto mais perto ou longe está de atingir o objetivo ou a meta (Prensky, 2007). As regras de um jogo "determinam o que "vale" dentro do mundo temporário por ele circunscrito" (Huizinga, 1996, p. 14). As regras definem o que pode e o que não pode ser realizado no jogo, direcionando as decisões dos jogadores e assegurando que todos os jogadores sigam caminhos semelhantes. De outro modo, as restrições são introduzidas como incentivos ou recursos como, por exemplo, dinheiro, energia ou vidas extras. Podem também determinar dependências, definindo que um jogador só poderá executar certas ações se as condições forem atendidas.

Ao analisarmos o modo como essas características se apresentam nos jogos digitais, destacamos que por suas características que combinam imagens, textos, sons e a interatividade (Greenfield, 1988, Kruger; Cruz, 2001), as quais podem se revelar de modo 
mais imediato, com potencial de envolver os jogadores, respeitando o ritmo dos jogadores e oferecendo feedbacks imediatos.

O elemento da narrativa de um jogo corresponde a história fictícia elaborada para conduzir o jogador e motivar as suas ações, pode ser apresentada por meio de vídeos, textos, animações, sons e imagens. Este elemento é bastante presente em jogos do tipo RPG (Role Playing Game), porém há jogos que não possuem narrativa (Kremers, 2009).

A interação refere-se ao modo como o jogo digital é efetivamente jogado, e pode acontecer com o ambiente do jogo, principalmente através do feedback por pontuação, fases ou níveis; ou interação social, quando os jogadores interagem entre eles (Prensky, 2007). Os jogos podem ser jogados por um único jogador (single-player), competindo contra ele próprio; pode ter muitos jogadores (multi-players), onde adversários competem entre si; ou ainda, o jogo pode ser jogado em grupos (multi-grupos), competindo com outros grupos (Balasubramanian \& Wilson, 2006). Conflito, competição, desafio ou oposição são problemas a serem resolvidos pelo jogador (Prensky, 2007) e esses elementos têm contribuições importantes para o engajamento e motivação do jogador.

A recompensa, por sua vez, refere-se a uma contribuição que o jogador recebe quando realiza uma tarefa ou cumpre um objetivo com sucesso, podendo ser apresentada como a disponibilização de novos recursos, a aquisição de novas habilidades, o recebimento de recursos ou algum destaque no jogo, a possibilidade de fazer ou ter coisas que antes não eram possíveis. Ao final do jogo, as recompensas típicas são de o jogador ser o vencedor, adquirir poderes e privilégios, ter uma pontuação maior em um ranking.

Por fim, o feedback é um elemento importante, especialmente em jogos educacionais, para mostrar os resultados obtidos pelo jogador, indicando claramente onde ele errou e acertou. De acordo com Salen e Zimmerman (2003), o feedback indica se o jogador está no caminho certo ou se suas ações são adequadas, sem isso o jogo torna-se pouco significativo.

A utilização de jogos como estratégia de ensino e aprendizagem também é conhecida como aprendizagem baseada em jogos (Games-Based Learning) (Prensky, 2007). Considerada uma abordagem inovadora (Tang, Hanneghan e El Rhalibi, 2009), reforça que a aceitação de jogos como estratégias de ensino e aprendizagem é cada vez maior (Monsalve, Werneck \& Leite, 2013). Os jogos educacionais potencializam uma aprendizagem ativa e mais significativa, baseada na experiência (Wagner, 1970; Bonwell \& Eison, 1991) e que contribuem na atenção e imersão do aluno na aprendizagem, mantendo a sua concentração até a vitória (Wangenheim \& Wangenheim, 2012). Os jogos, ainda, oferecem um ambiente 
divertido e seguro, onde o aluno pode experimentar alternativas e visualizar as consequências, aprendendo com os próprios erros (Pfahl, Ruhe and Koval, 2001).

No que se refere aos tipos de jogos, diversos autores tentaram classificar os jogos em gênero ou em tipologias semelhantes (Michael \& Chen, 2006; Susi, Johannesson \& Bachlund, 2007; Karner \& Härtel, 2011). No entanto, algumas classificações são muito amplas, abordando qualquer tipo de domínio, enquanto outras são bastante específicas, concentrandose em domínios únicos, como em educação em saúde, por exemplo. De forma geral, conforme a sua plataforma, os jogos podem ser classificados em digitais e não-digitais. Os primeiros envolvem a interação humana com uma interface de usuário para gerar feedback em um dispositivo eletrônico (Prensky, 2007). Esses jogos digitais ou eletrônicos são utilizados em diversas plataformas, tais como: computadores pessoais, consoles ou ainda em dispositivos móveis. Os jogos não- digitais são os jogos que não utilizam dispositivos eletrônicos, também conhecidos como jogos manuais e podem ser jogos de tabuleiro, cartas, lápis e papel ou de acessórios (Prensky, 2007). Embora ainda tenhamos a utilização de jogos não-digitais em ambientes educativos, atualmente, observa-se um crescimento gradativo na utilização de jogos educacionais digitais, sem que necessariamente um substitua o outro. Conforme o Censo da Indústria Brasileira de Jogos Digitais, o desenvolvimento de jogos educacionais digitais vem crescendo nos últimos anos e já representa cerca de 43,8\% dos jogos desenvolvidos no Brasil (FLEURY et al., 2014). Por este motivo, na próxima seção apresentamos as contribuições da neurociência à aprendizagem, dando uma atenção especial aos jogos educacionais digitais.

\section{JOGOS EDUCACIONAIS: CONTRIBUIÇÕES DA NEUROCIÊNCIA À APRENDIZAGEM}

Profissionais da área educacional, preocupados com sua prática pedagógica e didática, tem reconhecido cada vez mais o uso de jogos digitais como aliados para o desenvolvimento social, emocional e intelectual de seus alunos (Prensky, 2007; Ramos, 2013). Nesse sentido, destacamos que os jogos educacionais digitais, em particular, trazem inúmeras contribuições e benefícios para o jogador, contribuindo para que o momento de aprendizagem de algum conteúdo escolar específico aconteça de forma mais lúdica, multimodal, motivadora, prazerosa e divertida. Contudo, para que jogadores possam aprender efetivamente, os jogos 
devem ser usados com objetivos de aprendizagem e práticas pedagógico-didáticas muito bem definidos, a fim de promover o desenvolvimento de estratégias e de habilidades cognitivas (Gee, 2005; Gros, 2003; Prensky, 2007; Ramos, 2013; Savi \& Ulbricht, 2008; Squire, 2006).

Da mesma forma que se encontram várias contribuições a partir do uso do jogo, há também muitos exemplos de jogos, que variam em relação ao seu formato, material, regras e narrativas, níveis e missões, tempo, complexidade e objetivos, entre outros (Ramos, 2013). Cada um desses jogos possibilita e/ou privilegia o desenvolvimento de diferentes habilidades cognitivas. Há jogos clássicos, como o Genius, que possuem sua versão digital que exercitam a memória de trabalho, uma vez que para avançar nos níveis é preciso guardar a sequência de cores e reproduzí-las. Outros jogos envolvem fortemente a capacidade de resolução de problemas, que supõe a análise, o levantamento de hipóteses, o planejamento das ações, a realização e avaliação das ações. Em jogos como a Hora do Rush, tanto em sua versão digital como não-digital, é preciso mover vários carros, os quais se movimentam com certa restrição (regras) para que seja possível movimentar um carro específico (objetivo).

De modo a conceituar as habilidades cognitivas, consideramos que, de acordo com Parenté (1996), a cognição é uma coleção de funções mentais que incluem, entre outros aspectos, a atenção, concentração, percepção, compreensão, aprendizagem, memória, resolução de problemas e raciocínio, que permitem que o indivíduo compreenda e se relacione com o mundo social e seus elementos. Gazzaniga \& Heatherton (2005) afirmaram que existem quatro aspectos diferentes da função cognitiva, que são: a) a representação das informações; b) a resolução de problemas e a tomada de decisões; c) a inteligência e o pensamento lógico e verbal; e d) a consciência. A partir disso, podemos entender que as habilidades cognitivas se referem ao uso das funções mentais nas mais variadas atividades humanas. De acordo com Gatti (1997), as habilidades cognitivas podem ser entendidas como capacidades que tornam o sujeito competente e lhe permite interagir simbolicamente com o meio.

De acordo com Gros (2003), os jogos educacionais promovem o desenvolvimento intelectual, tendo em vista que para vencer os desafios e passar de nível, o jogador precisa entender como os diferentes elementos do jogo se relacionam, elaborar estratégias, tomar decisões, processar informações e resolver problemas, usando a criatividade.

Outro aspecto presente nos jogos refere-se ao seu potencial para gerar emoções, as quais podem funcionar como moduladores de nossas memórias que se refere a um componente fundamental da aprendizagem. De acordo com Tezani (2006), existem no jogo dois aspectos primordiais: um referente às emoções expressas durante a ação do jogo, como o 
prazer ou o medo; e outro referente aos aspectos cognitivos, por meio dos quais o jogo proporciona avanços nos processos de aprendizagem e desenvolvimento do jogador. Primeiramente, vamos lidar com cognição, para depois enfatizar os processos emocionais presentes nos jogos.

Vygotsky (2007) afirma que as funções psicológicas superiores, ou seja, aquelas funções mentais mais complexas que envolvem o controle consciente do comportamento, tais como percepção, atenção e memória, são originadas das relações entre os indivíduos humanos. Essas funções são influenciadas pelo grau de desenvolvimento, pelo domínio do uso de instrumentos e pelas interações sociais (Vygotsky, 2007).

Deste aspecto destacamos dois conceitos importantes que estão presentes nas práticas pedagógicas: a mediação e a zona de desenvolvimento proximal. A mediação, de acordo com Tezani (2006), seria um processo de intervenção de um elemento intermediário na relação de aprendizagem, ou seja, a relação deixa de ser direta e passa a ser mediada por esse elemento. A mediação está fortemente ligada aos processos que provocam uma apropriação de gestos, palavras, e ações do mediador, que exerce o papel de exemplo a ser seguido, provocando uma ação de imitação e reprodução pelo aprendiz de acordo com as suas condições cognitivas, afetivas, sociais e motoras (Tosta, 2012).

A importância da mediação nos remete a outro conceito importante de Vygotsky (2007), que é Zona de Desenvolvimento Proximal (ZDP), o qual considera que o aprendiz em cada momento de seu desenvolvimento, tem um nível de desenvolvimento real e um nível de desenvolvimento potencial. O primeiro representa a capacidade que a criança tem de realizar tarefas de forma independente, enquanto que o segundo seria sua capacidade de desempenhar tarefas com ajuda de outro indivíduo mais competente, e a distância entre esses dois níveis é a ZDP.

Assim, a ZDP diz respeito à distância entre o nível de desenvolvimento real (conquistas e capacidade de solucionar problemas de um aprendiz sem o auxílio do outro) e o nível de desenvolvimento potencial (solução de problemas por meio da mediação de adultos ou de parceiros mais capazes). Ao interferir na ZDP, um educador estará contribuindo para aprimorar os processos de desenvolvimento das funções mentais complexas da criança, o que pode ser interferência transformadora. Isso porque há tarefas que a criança não é capaz de realizar sozinha, mas será capaz de realizá-las se alguém lhe mediar, der instruções, fizer uma demonstração, fornecer pistas, ou lhe der assistência durante o processo. A ZDP refere-se, portanto, ao caminho que o indivíduo vai percorrer para desenvolver funções que estão em processos de amadurecimento e que se tornarão funções consolidadas, estabelecidas ao seu 
nível de desenvolvimento real. Desse modo, a ZDP está em constante transformação: aquilo que um aprendiz é capaz de fazer com a ajuda de alguém hoje, ele conseguirá realizar sozinho amanhã.

A partir destes conceitos mencionados, podemos verificar que o uso de jogos proporciona desafios que podem ser utilizados para exercitar o cérebro. As características dos jogos como os desafios e as regras criam contextos que exigem que o jogador fique atento aos estímulos relevantes dos jogos, coordene diferentes ações mantendo a meta a ser alcançada, planeje e avalie suas estratégias, utilizando funções mentais como a capacidade de atenção, de memória e resolução de problemas.

Nesse sentido, o jogo pode ser utilizado no contexto educacional para aprimorar as habilidades cognitivas ou abordar de forma lúdica os conteúdos escolares. No universo dos jogos, como seus cenários, narrativas e feedbacks, o jogador pode aproximar a teoria e a prática, fazendo uso de experiências anteriores para tornar a aprendizagem mais pessoal, atrativa e interessante. Além disso, ao fazer uso de seus conhecimentos prévios sobre estratégias do jogo, um jogador mais expert pode assumir o papel do professor e fazer uso da ZDP para auxiliar um colega jogador que está tendo dificuldades em passar de nível, cumprir missões ou resolver um problema no jogo.

As contribuições do uso dos jogos para os processos de desenvolvimento e aprendizagem, partem da compreensão de que os jogos podem criar experiências que geram aprendizagem e exercitam habilidades cognitivas. Então, concordamos com Vygostsky (2007) que o aprendizado e o desenvolvimento estão inter-relacionados ao promover experiências de aprendizagem afetando o desenvolvimento cognitivo, pois o "aprendizado adequadamente organizado resulta em desenvolvimento mental e põe em movimento vários processos de desenvolvimento que, de outra forma, seriam impossíveis de acontecer" (Vygostky, 2007, p. 103).

Para Vygotsky (1991/2002), a construção do conhecimento de cada indivíduo acontece de acordo com seus conhecimentos e suas experiências prévias, e envolve a utilização de diferentes instrumentos e símbolos como a linguagem e a tecnologia, o que aumenta as possibilidades de desenvolvimento mental. Quanto mais informações ou aprendizagens o indivíduo for exposto, como a escrita, o desenho, a música, o jogo, a leitura, etc., mais o cérebro se beneficiará seu desenvolvimento. Desse modo, o ensino escolar é importante, pois expõe o sujeito às ações de conscientização dos conceitos e de seus processos de pensamento. Assim, à medida que são aprendidos, os conteúdos escolares proporcionam o desenvolvimento de funções superiores, pois exigem habilidades como a abstração, a relação 
entre conceitos, a sistematização hierárquica e assim ampliam o grau de generalização dos conceitos (Lima et. al, 2008).

Salienta Rocha (2003) que, com as pesquisas atuais, os neurocientistas estão "se tornando capazes de demonstrar que o processo emocional pode ajudar ou atrapalhar o processo educacional" (p. 95). Dessa forma, ao abordarmos a aprendizagem, não se pode deixar de discutir as emoções envolvidas no processo de aprendizagem, o que pode ser resgatado através dos jogos. De acordo com a autora (ibid.), as emoções são responsáveis pela competência cognitiva em adultos e crianças. As principais estruturas do "cérebro emocional" são conhecidas coletivamente como sistema límbico, tendo como suas principais a amígdala e o hipocampo, que fazem conexões com o córtex frontal (Lent, 2013). Quando há medo ou tensão, presente muitas vezes em momentos na sala de aula, o desempenho cognitivo é prejudicado, de forma a comprometer a aprendizagem.

Desta maneira, os jogos educacionais e, em especial os digitais, diferenciam-se das situações vivenciadas em sala de aula, e, de modo geral, trazem um contexto mais relaxado e divertido (Prensky, 2007; Squire, 2006; Gee, 2005) e capaz de aumentar substâncias relacionadas com o prazer, como a serotonina, aumentando as chances de aprendizado em um ambiente descontraído. Nos jogos educacionais digitais, o jogador pode criar uma nova identidade, pode correr riscos, pode errar e tentar novamente, pode simular situações e resolver problemas sem pressão, medo, frustração, trazendo benefícios diretos relacionados ao processo de aprendizagem (Rocha, 2003).

\section{JOGOS EDUCACIONAIS E A APRENDIZAGEM DE LÍNGUAS ESTRANGEIRAS}

Como vimos anteriormente, jogos educacionais tem elementos como narrativa, interação, objetivos, regras, desafios e resultados (Prensky, 2007; Wangenheim \& Wangenheim, 2012), e fornecem ambientes seguros para desenvolvimento de processos cognitivos, como a atenção, a concentração e o raciocínio. Nesta seção, falaremos dos benefícios dos jogos educacionais para o aprendizado de línguas estrangeiras.

Embora o número de jogos educacionais específicos para o aprendizado de línguas estrangeiras ainda seja muito restrito, existe atualmente um número crescente de pesquisas relacionadas ao aprendizado de línguas estrangeiras através do uso de jogos educacionais, trazendo resultados motivadores (Squire, 2006; Chik, 2014; Tumolo, 2014; Lorenset, 2016). Estes jogos aplicados em sala de aula trazem a diversão e o prazer no ato de jogar, gerando 
sinais químicos no cérebro relacionados à recompensa, o que aumenta a probabilidade de repetição do comportamento. A recompensa está relacionada com a dopamina, que é um neurotransmissor que tem várias funções, dependendo de onde e quando é segregada (Wang \& Aamodt, 2012). Segundo Gee (2005), os momentos de diversão e descontração proporcionados pelos jogos educacionais desenvolvem no jogador motivação para continuar jogando, uma vez que passam a interagir com histórias permeadas por uma série de elementos que designam a continuidade do jogo. Além disso, estimulam a definição de metas e organização das ações a serem tomadas para enfrentar problemas, possibilitando a adaptação das experiências vivenciadas nos jogos para o contexto pessoal, social e escolar do jogador. Gee (2005) afirma ainda que os jogos podem ser usados de forma a suplementar o ensino tradicional das escolas, oferecendo, assim, aprendizagem situada em contexto.

Os jogos educacionais para o ensino de línguas estrangeiras são tipicamente utilizados para o ensino das quatro habilidades da língua (escrita, leitura, áudio e produção oral), focando geralmente na leitura e/ou áudio dos comandos a serem seguidos (Anderson et al, 2008; Peterson, 2009; Soares, 2013; Chen \& Yang, 2013; Tumolo, 2014). Além disso, os jogos digitais podem ser utilizados para o ensino de gramática, especificamente sintaxe e também ortografia (Tumolo, 2014; Soares, 2013), ou até mesmo para a expansão do vocabulário dos estudantes (Florence et al, 2006; Yanguas, 2009; da Silva, 2012; Saffarian \& Gorjian, 2012; Yudintseva, 2015). Além disso, observa-se ainda a utilização de jogos de entretenimento em línguas estrangeiras como recurso de ensino, cujo objetivo é inserir os estudantes no contexto real da língua estrangeira a ser ensinada, criando oportunidades de interação na língua alvo.

De acordo com Prensky (2007), a aprendizagem mediada por jogos educacionais digitais tem a especificidade de ser ao mesmo tempo divertida e participativa, além da aprendizagem e o entretenimento efetivos e interativos, o que contribui para que seja intrinsicamente motivadora para os jogadores. Em muitos jogos educacionais, o jogador cria uma nova vida virtual e vive em uma outra realidade propícia para o aprendizado e aquisição do conhecimento. Moura (2014), por exemplo, aponta que a aquisição de vocabulário ocorra principalmente por meio dos dos jogos em sala de aula, sobretudo pelo fato de os jogadores estarem imersos em um outro contexto e ter oportunidades de se comunicar e interagir na língua alvo de aprendizado. Jogos, portanto, podem ser adequados para aprender assuntos mais difíceis ou menos apreciados pelos alunos, como por exemplo, regras gramaticais e escrita formal, a fim de inserir motivação para o aprendizado. 
O fato do jogo se configurar como uma atividade motivadora e muitos jogos serem apresentados em língua inglesa, por exemplo, leva o jogador a buscar dominar e compreender essa língua para compreender melhor o jogo e interagir com ele. Uma pesquisa desenvolvida por Cruz, Ramos e Albuquerque (2012) com 322 estudantes de escolas de Santa Catarina para conhecer suas opiniões e ideias sobre jogos eletrônicos e o que aprendem por meio deles, revelou que a aprendizagem de outra língua foi a mais relatada pelos jovens, citando com frequência o inglês, e justificaram que "aprendem novas palavras ou exercitam o inglês, porque parte dos jogos está nesse idioma" (p. 93).

De modo geral, acredita-se que a situação ideal para o aprendizado de línguas estrangeiras pelas sessões de jogos é, ou a inserção de jogos educacionais específicos para ensino e aprendizagem de línguas estrangeiras, ou a inclusão de jogos para entretenimento na língua alvo, a fim de criar ambientes imersos na língua estrangeira para, desta forma, aumentar oportunidades de interação do jogador com a língua que ele deseja aprender. Deste modo, contribuindo para a criação de um contexto de aprendizagem que possua os elementos que todo professor gostaria de ver na sala de aula, conforme Leffa \& Pinto (2014): motivação, interesse, aprendizagem, negociação e desenvolvimento da colaboração nos alunos. Jogos, portanto, são capazes de motivar o aluno e de desenvolver a aprendizagem da língua alvo através do feedback, que pode levar ao fluxo e que, por sua vez, pode levar à concentração de energia e à superação do sujeito, contribuindo significativamente para aprendizagem de línguas estrangeiras, especialmente nos estágios iniciais de aquisição de vocabulário.

Para concluir, os jogos conseguem fazer com que os aprendizes fiquem horas sentadas diante deles, mesmo depois de um dia cansativo, tentando atingir resultados, vibrando com suas conquistas e determinados a superar seus objetivos e metas. Como plano de fundo, porém, o aprendizado ocorre, aumentando a motivação e criando oportunidades de trocas, interação e exposição à língua alvo de aprendizagem. As características dos jogos educacionais e a forma como os jogadores atuam nesses espaços virtuais podem ser relacionados aos conceitos da neurociência, os quais nos proporcionam uma maior compreensão de como os jogos, tanto educacionais quanto para entretenimento, podem ampliar as possibilidades de assimilação e aprendizado de novos conhecimentos pelo jogador.

\section{CONSIDERAÇÕES FINAIS}

Como vimos nas seções anteriores, os jogos contribuem com o aprimoramento da função simbólica, da imaginação, da criatividade, da linguagem, trabalhando com os limites 
existentes entre a vida real e a virtual, fornecendo ao jogador possibilidades de conhecer, interpretar e testar os fenômenos à sua volta (Fernández, 1990). Dessa maneira, podemos considerar que jogos representam momentos de aprendizagem significativa, relaxada, motivada, descontraída, que ressaltam o conhecimento e o aprendizado como algo mais amplo do que o contexto escolar permite, ressaltando e integrando ao jogo às experiências e conhecimentos pessoais que cada jogador traz consigo. Com esta finalidade, o uso dos jogos pode auxiliar todo o processo de aprendizagem e de desenvolvimento cognitivo, afetivo e emocional. Partindo do ponto de vista de que a aprendizagem é a apropriação do objeto de conhecimento, por meio das constantes interações entre criança, meio e objeto de conhecimento, jogar em sala de aula proporcionaria momentos ricos em interação e aprendizagem, tanto para educadores quanto para alunos/jogadores.

Os jogos educacionais oferecem diversas possibilidades de aprendizagem, proporcionando experiências que contribuem com o aprimoramento de habilidades cognitivas e processos emocionais. Além de melhorar e auxiliar no aprendizado de uma língua estrangeira, como citado anteriormente, jogos educacionais também podem ir além e a) auxiliar no aprendizado de inteligências múltiplas; b) desenvolver e ampliar habilidades cognitivas, como a atenção e a concentração, que vão posteriormente beneficiar o tempo de estudo e leitura focada do jogador; c) no desenvolvimento motor; d) na socialização e na interação com outros jogadores; entre outros. Todos os aspectos do jogo mencionados acima podem ser levados para experiências da vida real, fazendo com que o jogador tenha mais flexibilidade, sociabilidade, ajudando-o a manter a atenção quando necessário, da mesma forma que facilita a resolução de problemas utilizando diversas estratégias aprendidas no jogo.

Os jogos digitais atualmente estão tão realistas que podem ser vistos como um ensaio da vida real. Acredita-se, dessa forma, que os jogos também possam resgatar o desejo pela busca de conhecimento e tornar a aprendizagem mais prazerosa, por meio da qual o aluno/jogador passe a gostar cada vez mais de aprender e de conhecer o mundo ao seu redor.

\section{REFERÊNCIAS BIBLIOGRÁFICAS}

ABT, C.C. Serious Games. Lanham, MD: University Press of America, 2002.

ANDERSON, T. A. F. et al. Video Games in the English as a Foreign Language Classroom. In: $2^{\text {nd }}$ IEE International Conference on Digital Games and Intelligent Toys Based Education. Banff: IEE Press: 2008, pp. 188 - 192. 
BALASUBRAMANIAN, N. \& WILSON, B. G. Games and Simulations. Disponível em: http://www.coulthard.com/library/(balasubramanian\%20\%26\%20wilson,\%202005).html

BONWELL, C. C \& EISON J. A. Active Learning: Creating Excitement in the Class room. Washington, EUA: EricDigests, 1991.

CHEN, H. H. \& YANG, T. C. The impact of adventure video games on foreign language learning and the perceptions of learners. Interactive Learning Environments, v. 21, n. 2., pp.129-141, 2013.

CHIK, A. Digital gaming and language learning: Autonomy and community. Language Learning \& Technology, v. 18, n.2, pp. 85-100, 2014.

DA SILVA, E. B. et al. Jogos eletrônicos em língua inglesa: aspectos quantitativos do conteúdo lexical. Via Litterae: Revista de Linguística e Teoria Literária, v.4, n. 1, pp. 5362, jan./jun. 2012.

DEMPSEY, J. V. et al. Instructional applications of computer games. Apresentação no evento Annual Meeting of the American Educational Research Association (AERA), 1996.

CRUZ, D. M.; RAMOS, D. K.; ALBUQUERQUE, Rafael Marques. Jogos eletrônicos e aprendizagem: o que as crianças e jovens têm a dizer?. Revista Contrapontos, v. 12, n. 1, pp. 87-96, 2012.

FERNÁNDEZ, A. A inteligência aprisionada: abordagem psicopedagógica clínica da criança e sua família. Porto Alegre: Artmed. 1990.

FLEURY, A.; SAKUDA, L. O.; CORDEIRO; J. H. D. O. $1^{\circ}$ Censo da Indústria Brasileira de Jogos Digitais. GEDIGames, NPGT, Escola Politécnica, 2014. Disponível em: <http://www.bndes.gov.br/SiteBNDES/bndes/bndes_pt/Galerias/Arquivos/conhecimento/sem inario/seminario_mapeamento_industria_games042014_RelApoioCensoIndustriaBrasileirade Jogos.pdf> Acesso em: 02 maio 2016.

FLORENCE, W. M. et al. Online vocabulary games as a tool for teaching and learning English vocabulary. Educational Media International, v. 43, n. 3, pp.233-249, set/2006.

GATTI, B. A. Habilidades cognitivas e competências sociais. Laboratorio Latinoamericano de Evaluación de la calidad de la educación. LLECE, OREALC/UNESCO: Santiago, 1997. Retirado em 10/07/2015 de http://unesdoc.unesco.org/images/0018/001836/183655por.pdf

GAZZANIGA, M. S. \& HEATHERTON, T. F. Cognição. In: GAZZANIGA, M. S. \& HEATHERTON, T. F. Ciência psicológica: mente, cérebro e comportamento. Porto Alegre: Artmed, 2005, pp.248-277.

GEE, J. P. Good video games and good learning. Phi Kappa Phi Forum, v.85, n.2, pp. 34$37,2005$.

GRAMIGNA, M. R. Jogos de Empresa. Pearson Education: São Paulo. 2007. 
GREENFIELD, P. O desenvolvimento do raciocínio na era eletrônica: os efeitos da TV, computadores e videogames. São Paulo: Summus, 1988.

GROS, B. The impact of digital games in education. First Monday, v. 8, n. 7, pp.1-21, jul/ 2003.

HINEBAUGH, J. P. A Board Game Education. Lanham, MD: Rowman \& Littlefield Publishers, 2009.

HUIZINGA, J. Homo ludens: o jogo como elemento da cultura. Editora Perspectiva: São Paulo,1996.

KARNER, F. W. \& HÄRTEL, G. Theory and Taxonomies of Serious Games. ENTRExplorer Project. 2011. Retirado em 15/05/2015 de http://www.entrexplorer.com/pdf/Theory_and_Taxonomies_of_Serious_Games.pdf

KREMERS, R. Level Design: Concept, theory, and practice. Natick, MA: AK Peters, 2009.

KRÜGER, F. L.; CRUZ, D M. Os jogos eletrônicos de simulação e a criança. Congresso Brasileiro da Comunicação, 24, 2001. Anais do Congresso Brasileiro da Comunicação. Campo Grande: Intercom 2001, pp. 1 -16.

LEFFA, V. J. \& PINTO, C. M. Aprendizagem Como Vício: O Uso de Games na Sala de Aula. In: (Con) textos Linguísticos, v. 8, pp. 358-378, 2014.

LENT, R. Neurociência da mente e do comportamento. Rio de Janeiro: Guanabara Koogan, 2013.

LIMA, M. F. et al. Funções Psicológicas Superiores e a Educação Escolar: Uma Leitura Crítica a partir de Vygotsky. Verinotio - Revista On-line de Educação e Ciências Humanas, n. 8, ano IV, pp.1-22, 2008.

LORENSET, C. C. Motivation and Digital Games for English as a Second Language Learning. XIII EVIDOSOL e X CILTEC-Online, 2016 (Online). V Anais do Evidosol/Ciltec-online, v. 5, pp. 137-142, 2016.

MICHAEL, D. \& CHEN, S. Serious games: games that educate, train, and inform. , Boston, EUA: Thomson Course Technology, 2006.

MONSALVE, E., WERNECK, V. \& LEITE, J. C. S. P. SimuleES-W: Retroalimentação Evolutiva num Jogo para Ensino na Engenharia de Software. FEES 2013 - Fórum de Educação em Engenharia de Software, 2013. Brasília. Anais do Fórum de Educação em Engenharia de Software. Salvador, pp. 20-38, 2013.

MORAN, J. A integração das tecnologias na educação. 2013. Retirado em 26/06/2015 de http://www.eca.usp.br/prof/moran/site/textos/tecnologias_eduacacao/integracao.pdf.

MOURA, A. Jogos Eletrônicos para Aprendizagem Curricular em Língua Materna e Estrangeira. Conference paper: $9^{\mathbf{a}}$ Conferencia Ibérica de Sistemas y Tecnologias de Información, Barcelona, Spain, Vol. II, 2014. 
PARENTÉ, R. Retraining Cognition: techniques and applications. Aspen Publishers: Maryland, 1996.

PETERSON, M. The Use of Computerized Games and Simulations in Computer-Assisted Language Learning: A Meta-Analysis of Research. Simulation \& Gaming, v.1, n.41,pp.7293, dez/ 2009.

PFAHL, D., RUHE, G. \& KOVAL, N. An Experiment for Evaluating the Effectiveness of Using a System Dynamics Simulation Model in Software Project Management Education. $7^{\text {th }}$ International Symposium on Software Metrics, London/Great Britain, 2001.

PRENSKY, M. Digital Game-Based Learning. New York: Paragon House, 2007.

RAMOS, D. K. Jogos cognitivos eletrônicos: contribuições à aprendizagem no contexto escolar. Ciências \& Cognição (UFRJ), v.18, pp. 19-32, 2013.

ROCHA, E. A aprendizagem vista de uma perspectiva neurocientífica. Compreendendo o cérebro: rumo a nova ciência do aprendizagem. São Paulo: SENAC, 2003.

SAFFARIAN, R., \& GORJIAN, B. Effect of computer-based video games for vocabulary acquisition among young children: An experimental study. Journal of Comparative Literature and Culture (JCLC), v.1. n.3, pp.44-48, 2012.

SALEN, K. \& ZIMMERMANN, E. Rules of Play: Game Design Fundamentals. MIT Press. 2003.

SAVI, R. \& ULBRICHT, V. R. Jogos Digitais Educacionais: benefícios e desafios. Novas Tecnologias na Educação - CINTED-UFRGS, v. 6, n. 1, pp.1-10, dez/ 2008.

SANTAELLA, L., FEITOZA, M. Introdução. IN: SANTAELLA, L., FEITOZA, M. Mapa do jogo: a diversidade cultural dos games. São Paulo: Cengage Learning, 2009.

SOARES, W. C. da S. A aprendizagem de inglês mediada por jogos eletrônicos do tipo MMORPG. 2013. 105 f. Dissertação (Mestrado em Linguística Aplicada; Literatura Comparada) - Universidade Federal do Rio Grande do Norte, 2013.

SQUIRE, K. From Content to Context: Videogames as Designed Experience. Educational Researcher, v.3, n.8, pp.19-29, 2006.

SUSI, T., JOHANNESSON, M. \& BACKLUND, P. Serious Games - an overview. Technical Report HS-IKI-TR-07-001. University of Skövde, Sweden:2007.

TANG, S., HANNEGHAN, M. \& EL RHALIBIBI, A. Introduction to Games-Based Learning. In: CONNOLLY, T., STANSFIELD, M.H. , BOYLE, L. (Eds) Games-based Learning Advancement for Multisensory Human Computer Interfaces: Techniques and Effective Practices.Hershey, PA: IGI Global, 2009.

TEZANI, T. C. R. O jogo e os processos de aprendizagem e desenvolvimento: aspectos cognitivos e afetivos. Educação em Revista, v.7, n. 1, pp. 1-16, 2006. 
THOMPSON, J., BERBANK-GREEN, B. \& CUSWORTH N. Game Design: Principles, Practice, and Techniques - The Ultimate Guide for the Aspiring Game Designer. London: Wiley. 2007.

TOSTA, C. G. Vygotsky e o Desenvolvimento das Funções Psicológicas Superiores. In: Perspectivas em Psicologia, v. 16, n.1, pp. 57-67, jan/jun 2012.

TUMOLO, C. Recursos digitais e aprendizagem de inglês como língua estrangeira. Ilha do Desterro, v.1, n.66, pp.203 - 238, jan/jun 2014.

VYGOTSKY, L. S. A formação social da mente. 7.ed. São Paulo: Martins Fontes, 2007.

WAGNER, R.W. Edgar Dale: Professional. Theory into Practice, v.9, n.2, pp. 89.95, 1970.

WANG, S.\& AAMODT, S. Play, Stress, and the Learning Brain. Cerebrum, September 24, 2012. Retirado em 25/02/2015 de http://dana.org/news/cerebrum/detail.aspx?id=39402

WANGENHEIM, C. G. \& WANGENHEIM, A. Ensinando Computaçao com Jogos. Florianópolis/SC: Bookes Editora, 2012.

YANGUAS, I. Multimedia Glosses and Their Effect on L2 Text Comprehension and Vocabulary Learning. Language Learning \& Technology, v. 13, n. 2, pp. 48-67, jun/2009.

YUDINTSEV, A. Game-Enhanced Second Language Vocabulary Acquisition Strategies: A Systematic Review. Open Journal of Social Sciences 2015, v. 03, n.10, pp.101-119, 2015. 